\title{
Wnt Signaling: Pathogen Incursion and Immune Defense
}

\author{
Suborno Jati ${ }^{1}$, Tresa Rani Sarraf ${ }^{1}$, Debdut Naskar ${ }^{2 *}$ and Malini Sen ${ }^{1 *}$ \\ ${ }^{1}$ Division of Cancer Biology and Inflammatory Disorder, Indian Institute of Chemical Biology, Kolkata, India, ${ }^{2}$ Department of \\ Biotechnology, Maulana Abul Kalam Azad University of Technology, Kolkata, India
}

Wht ligands interact with the transmembrane cell surface receptors Frizzled and ROR/RYK to initiate complex signaling cascades that are crucial for cell physiology and the proper functioning of the immune system. Wnt signaling is instrumental in maintaining immune surveillance and during infections by pathogenic microbes helps mount host resistance to infection. Some pathogens, however, utilize Wnt signaling to build a niche for their survival. The goal of this review is to summarize current and developing concepts about the tug of war between Wnt signaling and pathogens for deployment of host resources, focusing mostly on macrophages and cytoskeletal actin

OPEN ACCESS

Edited by:

lan Marriott,

University of North Carolina at Charlotte, United States

Reviewed by:

Jere W. McBride,

University of Texas Medical Branch at Galveston, United States

Elsa Anes,

University of Lisbon, Portugal

Laurel L. Lenz,

School of Medicine, University of Colorado Denver, United States

*Correspondence: Debdut Naskar debdut1984@gmail.com Malini Sen

msen648@gmail.com; msen@iicb.res.in

Specialty section: This article was submitted to Microbial Immunology, a section of the journal

Frontiers in Immunology

Received: 24 June 2019 Accepted: 15 October 2019 Published: 29 October 2019

Citation:

Jati S, Sarraf TR, Naskar D and Sen M (2019) Wnt Signaling: Pathogen Incursion and Immune Defense. Front. Immunol. 10:2551 doi: 10.3389/fimmu.2019.02551 dynamics. An additional objective is to outline the interrelation between Wnt signaling and the host microbiota, which is vital for immune defense, discussing in the same perspective, how Wnt signaling could be differentiating pathogen from non-pathogen.

Keywords: Wnt, frizzled, pathogen, microbiota, actin, cytoskeleton, macrophage, immunity

\section{INTRODUCTION}

Macrophages, major sentinels of immune defense utilize the Wnt signaling scheme to sustain immune homeostasis, maintain immune surveillance, and combat infections with several pathogens. Some microorganisms, however, outmaneuver Wnt signaling and exploit it to create a niche for their survival. Wnt associated cytoskeletal modulations and transcriptional programs partake of such host pathogen interactions (1-8). Wnt signaling is also linked with the colonization of distinct groups of microbiota, which coexist with the host and bolster immune defense by inhibiting the growth of pathogenic microbes $(9,10)$.

Wnt proteins constitute a family of about 19 different secreted cysteine-rich glycoproteins in mammals, which are highly conserved among different species. Nusse et al. first identified the mammalian counterpart of Drosophila Wingless and termed it Wnt1, which nomenclature wise is a combination of Drosophila Wingless and the mouse proto-oncogene Int1 (11-13). The role of Wnt (Wingless) signaling was first documented during Drosophila development (11, 1315). Subsequently, with the identification of Wnt homologs in mammals the importance of Wnt signaling was recognized in the context of different cellular functions ranging from cell proliferation and migration to cell polarity and tissue homeostasis (16). Wnt signaling initiates when Wnt ligands interact with the Frizzled and ROR or RYK family cell surface receptors. While the Frizzleds (about 12 in number) are transmembrane proteins resembling heterotrimeric $G$ protein coupled receptors, ROR1, ROR2, and RYK resemble tyrosine kinases $(12,17-22)$. Due to considerable homology among different members of the Wnt and Frizzled families, it is possible for a particular Wnt ligand to interact with multiple Frizzled receptors (23). Thus, the outcome of Wnt-Frizzled signaling depends on the prevailing stoichiometry of the Wnt and Frizzled proteins and their mutual accessibility (24). Wnt-ROR/RYK signaling, mostly described as independent of Wnt-Frizzled signaling has also been shown to support Wnt-Frizzled signaling in some cases (21). A general scheme for Wnt signaling has been described in several review articles $(25,26)$. 
Wnt signaling can be categorized into two main classescanonical $(\beta$-catenin dependent) and non-canonical $(\beta$-catenin independent). In canonical Wnt signaling, $\beta$-catenin, which accumulates in the cytoplasm, enters into the nucleus acting as a transactivator for LEF/TCF transcription factors to initiate expression of $\beta$-catenin responsive genes (27). In non-canonical Wnt signaling, transcriptional activation is mostly associated with transcription factors such as NFKB, NFAT, and AP1 (6, $28,29)$, and cell polarity is linked with modulations of the cytoskeleton that involve actin and actin associated proteins (3032). The ligands Wnt3A and Wnt5A are usually considered as representatives of the canonical and non-canonical modes of Wnt signaling, respectively (33). Since Wnt signaling is guided and controlled by fairly homologous receptors and intracellular signaling intermediates that may be shared by both canonical and non-canonical modes of Wnt signaling, overlap between these two signaling pathways is not uncommon. Quite interestingly, the intracellular adaptor molecule Disheveled and Daple are required for both modes of Wnt signaling (34-36). Disheveled utilizes cholesterol, and the heterotrimeric G proteins coupled to Frizzled receptors interact with Daple for switching between the canonical and non-canonical modes (37). It is important to know if cooperation of the heterotrimeric $G$ proteins is required for Disheveled function during signaling $(36,38)$. Cell surface co-activator receptors such as Lipoprotein Receptor-like Protein (LRP) 5/6 are usually associated with only the canonical mode of Wnt signaling. Although LRP5/6 has been shown to interact with the non-canonical Wnt signaling ligand Wnt5A $(24,39)$, whether it is actually required for non-canonical Wnt signaling or acts to strike a balance between the canonical and non-canonical modes remains unsettled. A recent report suggests that Wnt can also signal by binding to TLR4/2 receptors (40). While Wnt-TLR signaling is important in view of the evolving role of Wnts in immunity to infections, the mode of this signaling pathway in relation to the already established intracellular signaling adaptors and intermediates remains to be documented.

Although it is now clear that Wnt signaling is closely associated with infection, sustenance of host microbiota and immune regulation $(3-6,9)$, interrelations between Wnt signaling and host immunity to different types of infection are complex and the molecular details therein are not yet settled. The goal of this review is to summarize current and developing concepts relating to the role of $\mathrm{Wnt}$ signaling in microbial infections with special emphasis on macrophages and cytoskeletal actin. The idea is to address unanswered yet important questions based on existing knowledge and paradigms to help bridge gaps in our understanding of the Wnt signaling scheme in the context of host immune defense programs.

\section{INTERRELATION BETWEEN WNT SIGNALING AND INFECTION WITH PATHOGENIC MICROBES}

Wnt signaling in macrophages plays a crucial role in shaping the outcome of infections by different pathogens (3, 4, 41-43). While Wnt signaling facilitates elimination of certain infections by disabling the causative pathogens, it also favors the progression of other infections by allowing the causative pathogen to build its niche within macrophages. It is expected that such interactions of host Wnt signaling with the encountered pathogens would involve actin cytoskeletal dynamics, an integral component of host pathogen interactions $(32,44,45)$. We will focus on some representative microbial infections in this regard.

\section{Bacterial Infection}

Infection by bacterial pathogens such as Pseudomonas sp. and Streptococcus sp. is inhibited by Wnt signaling. Wnt induced bacterial clearance in macrophages occurs by phagocytosis and subsequent xenophagy through utilization of the host actin associated autophagy circuit. In this context, the function of Wnt5A, which mediates cytoskeletal actin modulations through activation of the actin associated proteins Racl and Disheveled holds considerable significance $(3,4,36)$. It has been demonstrated that Wnt5A signaling in macrophages not only facilitates internalization of pathogenic Pseudomonas sp. and Streptococcus sp., but also enhances their killing. Wnt5ARac1/Disheveled dependent cytoskeletal actin rearrangements facilitate the formation of bacteria containing autophagosomes that are destined for lysosomal fusion, thus enabling bacterial clearance (3). Rac1 and Disheveled inhibitors, as well as Cytochalasin D which inhibits actin assembly, suppress Wnt5A mediated killing of Pseudomonas and Streptococcus. Signaling by Wnt3A and Wnt11 in macrophages and macrophage associated cells of the gut has also been linked with inhibition of infections by pathogenic Pseudomonas and Salmonella species $(43,46)$. It is important to know if cytoskeletal modulations as observed in the case of Wnt5A signaling are also associated with reduction of bacterial pathogen load by Wnt3A and Wnt11.

The Human Monocytotropic Ehrlichiosis (HME) causing bacterium Ehrlichia chaffeensis is yet another bacterial pathogen that interacts with Wnt signaling in macrophages. Unlike some of the other bacteria, E. chaffeensis utilizes both so called canonical and non-canonical Wnt signaling intermediates for niche building and multiplication within macrophages. Infection by E. chaffeensis is accompanied by increase in activation of the Wnt signaling intermediates Rac1 and Disheveled (8). Blockade in expression of Wnt5A, its putative receptor Frizzled5 and Rac1 furthermore, leads to decrease in E. chaffeensis infection (8), suggesting that Wnt5A signaling is needed for promoting $E$. chaffeensis intracellular niche formation. Interestingly, blockade in Wnt5A signaling also inhibits infection by the non-pathogenic lab strain of $E$. coli, DH5- $\alpha$, which gets internalized but not killed by activation of Wnt5A signaling (5). Wnt5A induced internalization of $E$. coli $\mathrm{DH} 5-\alpha$ is dependent upon alterations in actin assembly, which are not conducive to bacterial killing (5). Whether similar alterations in actin assembly are also associated with $E$. chaffeensis infection and niche formation will be important to decipher.

Wnt signaling in macrophages also regulates infection by different Mycobacterium species. Mycobacterial infections are associated with altered expression of several Wnts (47-51). While Wnt5A has been reported to promote both pro inflammatory and anti-inflammatory cytokine signatures in mycobacterium 
infected macrophages, both Wnt3A and Wnt6 have been reported to skew the intracellular milieu of infected macrophages toward an anti-inflammatory cytokine signature $(47,49,52,53)$. Recently, Gao et al. has demonstrated that Wnt5A restricts niche formation in macrophages by both Mycobacterium tuberculosis and Mycobacterium bovis through activation of autophagy (54). In light of the documented role of Wnt5 A signaling in cytoskeletal modulations and autophagy / xenophagy (3, 4, 30, 31 ), and the crucial involvement of actin and actin binding proteins during mycobacterial infections (55-57), it is important to examine how Wnt mediated cytoskeletal modulations regulate the sustenance vs. inhibition of mycobacterial infections.

\section{Parasitic and Fungal Infection}

Several lines of evidence indicate that Wnt signaling in macrophages regulates parasitic and fungal infections. Wnt5A signaling suppresses infection by the parasite Leishmania donovani, the causative agent of visceral leishmaniasis by blocking the sustenance of $L$. donovani containing parasitophorous vacuoles within macrophages. Transmission electron microscopy of $L$. donovani infected macrophages has revealed the predominance of degraded parasitophorous vacuoles in autophagosome like intracellular vesicles upon activation of Wnt5A signaling (4). Wnt5A mediated cytoskeletal alterations correlate with parasitophorous vacuole degradation and inhibition of infection. As in the case of bacterial infection, Wnt5A mediated inhibition of $L$. donovani infection is blocked by inhibitor of Racl activation, which is linked with Wnt5A mediated cytoskeletal alterations (4). Inhibition of Wnt5A production in vivo by intravenous administration of the inhibitor IWP2 into mice accordingly results in increased susceptibility to $L$. donovani infection (4). $L$. donovani infection in mice reportedly is sustained through a skewed hematopoiesis/myelopoiesis program marked by the predominant prevalence of inflammatory monocytes (58-60). Myelopoiesis and macrophage differentiation under normal conditions are supported by a complex Wnt signaling network that includes Wnt5A $(6,61-64)$. Thus, sustenance vs. inhibition of $L$. donovani infection is perhaps determined by the diverse traits of Wnt signaling in the context of the infection load. It is important to carry out a detailed evaluation of the role of Wnt5A in the context of other Wnts in this respect, especially in light of the documented antagonism of Wnt5A-actin network toward L. donovani infection (4).

The parasite Trypanosoma cruzi, which causes Chagas disease, unlike L. donovani exploits Wnt signaling for survival as is evident from the diminution of the intensity of T. cruzi infection through inhibition of transcriptional activation by $\beta$-catenin. $T$. cruzi infection increases expression of several Wnt ligands and Frizzled receptors, including Wnt5A, Wnt3A, Frizzled 4, Frizzled 8, Frizzled 9, and Frizzled 6 (7). Detailed analysis of Wnt-Frizzed signaling pathways in relation to T. cruzi infection should unveil the molecular mechanism of intracellular niche building by the parasite and the involvement of cytoskeletal actin therein.

Similar to L. donovani infection, and unlike T. cruzi infection, fungal infection of macrophages by Aspergillus fumigatus is inhibited by Wnt5A signaling. Migration and accumulation of neutrophils caused by Erk1/2 and JNK mediated increase in production of Wnt5A after Dectin1/Lox1 assisted intracellular entry of the fungus have been identified as a cause for the fungal clearance (65). It is important to examine if secreted Wnt5A and actin alterations are directly involved in recruiting neutrophils and activating macrophages for phagocytic clearance of A. fumigatus.

\section{Overview of Wnt-Pathogen Interactions}

In summary, it appears from the cited examples of different host pathogen interactions that the effect of Wnt signaling on pathogen infection is dependent on the type of the pathogen. Table 1 summarizes the different interrelations between Wnt signaling and pathogen infections. Although Pseudomonas sp. /Streptococcus sp., L. donovani and A. fumigatus are genotypically dissimilar and exercise different modes of action to infect the host (66-68), activation of Wnt5A signaling inhibits initiation of infection by all of these pathogens independent of their genotypic differences perhaps by inducing alterations in actin assembly which are incompatible with pathogen survival. Wnt mediated cytoskeletal alterations may also be crucial for the regulation of infection by T. cruzi and Mycobacterium.

In light of reports of existing links between cytoskeletal modulation and transcription factor translocation in immune cells $(69,70)$, it remains to be seen if activation of immune response associated transcription factors such as NFKB, NFAT, or AP1 correlates with cytoskeletal actin alterations during pathogen clearance facilitated by Wnt signaling. Wnt5A signaling, nevertheless, has been described in separate studies to sustain nuclear translocation of NFKB in macrophages both in the steady state and in response to mycobacterial infection, thereby maintaining expression of $\mathrm{NF} \mathrm{B}$ responsive immune response genes as a potential means of host resistance (6, $50)$. The requirement of $\mathrm{NF} \kappa \mathrm{B}$ mediated gene transcription for immunity to bacterial infections has, furthermore, been independently documented (71-73). Wnt5A signaling can also influence transcriptional regulation of immune response genes such as TNF $\alpha$, IFN $\gamma$, and IL6, which have interrelation with actin dynamics and are known to work toward inhibition of pathogen infection $(2,5,6,74-77)$. It will be interesting to find out how cytokine associated actin dynamics directly links with inhibition of pathogen infection.

Cytoskeletal alterations and transcriptional networks associated with the interaction of pathogens with different degrees and types of Wnt signaling are clearly complex. Careful analyses of further in depth studies with special attention to the different study approaches used by different laboratories are needed in order to establish how the different Wnt molecules work to accommodate or annihilate different pathogens through diverse signaling pathways.

\section{INTERRELATION BETWEEN WNT SIGNALING AND THE HOST MICROBIOTA}

Several anatomical locations in the human host serve as home to distinct congregations of bacteria (microbiota) that synchronize 
TABLE 1 | Wnt signaling and host-pathogen interaction.

\begin{tabular}{|c|c|c|c|c|c|}
\hline S.no. & Pathogen & Disease & $\begin{array}{l}\text { Associated Wnt } \\
\text { homolog }\end{array}$ & Host-pathogen interaction & References \\
\hline \multirow[t]{2}{*}{1.} & $\begin{array}{l}\text { Pseudomonas sp., } \\
\text { Streptococcus sp. }\end{array}$ & $\begin{array}{l}\text { Respiratory diseases } \\
\text { (e.g., COPD, sepsis etc.) }\end{array}$ & Wnt5a, Wnt3A & $\begin{array}{l}\text { Wnt5a-RAC1-Disheveled mediated cytoskeletal actin rearrangement } \\
\text { facilitates autophagy and containment of infection. }\end{array}$ & (3) \\
\hline & & & & $\begin{array}{l}\text { Wnt3A mediated increase in antimicrobial peptides causes killing of } \\
\text { Pseudomonas. }\end{array}$ & $(46)$ \\
\hline 2. & Salmonella sp. & $\begin{array}{l}\text { Inflammatory bowel } \\
\text { disease (IBD), Typhoid }\end{array}$ & Wnt11 & $\begin{array}{l}\text { Wnt11 signaling protects the host from bacterial infection and } \\
\text { inhibits apoptosis in intestinal cells. }\end{array}$ & $(43)$ \\
\hline 3. & Ehrlichia chaffeensis & $\begin{array}{l}\text { Human monocytotropic } \\
\text { ehrlichiosis (HME) }\end{array}$ & Wnt5a, Wnt10, Wnt6 & $\begin{array}{l}\text { Wnt ligands and associated signaling pathway ( } \beta \text {-catenin mediated, } \\
\text { NFAT-C1 mediated and others) promotes survival of the pathogen } \\
\text { inside the host. }\end{array}$ & (8) \\
\hline \multirow[t]{4}{*}{4.} & $\begin{array}{l}\text { Mycobacterium } \\
\text { tuberculosis }\end{array}$ & Tuberculosis & Wnt5a, Wnt3A, Wnt6 & $\begin{array}{l}\text { Mycobacterium infection promotes Wnt5A expression in human } \\
\text { PBMC and blockade of Wnt5A signaling results in inhibition of } \\
\text { IL-12p40 and IFN } \gamma \text { secretion. Mycobacterium infection } \\
\text { downregulates Wnt5A expression in mouse lungs. }\end{array}$ & $(47,50)$ \\
\hline & & & & $\begin{array}{l}\text { Enhanced IL36 } \gamma \text { secretion during infection induces Wnt5A } \\
\text { expression which aids in controlling infection through COX-2 } \\
\text { mediated autophagy. }\end{array}$ & $(54)$ \\
\hline & & & & $\begin{array}{l}\text { Wnt3A promotes an anti-inflammatory effect in murine macrophages } \\
\text { during infection in lungs. }\end{array}$ & $(49,52,53)$ \\
\hline & & & & $\begin{array}{l}\text { Mycobacterium infection induces Wnt6 expression and promotes } \\
\text { anti-inflammatory phenotype of macrophages through Arginase-1 } \\
\text { expression. }\end{array}$ & $(47)$ \\
\hline 5. & $\begin{array}{l}\text { Leishmania } \\
\text { donovani }\end{array}$ & $\begin{array}{l}\text { Visceral leishmaniasis } \\
\text { (Kala azar) }\end{array}$ & Wnt5a & $\begin{array}{l}\text { Wnt5A-Rac1-Rho mediated cytoskeletal alteration promotes } \\
\text { enhanced fusion of parasitophorous vacuole with lysosome which } \\
\text { helps in restraining infection. }\end{array}$ & (4) \\
\hline \multirow[t]{2}{*}{6.} & Trypanosoma cruzi & Chagas disease & Wnt3a, Wnt5a & $\begin{array}{l}\text { T. cruzi early infection increases expression of Wnt5A, 3A, several } \\
\text { Frizzled receptors, and Wnt signaling intermediates. }\end{array}$ & $(7)$ \\
\hline & & & & $\begin{array}{l}\text { Activation of } \beta \text {-catenin promotes inhibition of inflammatory cytokine } \\
\text { secretion and replication of parasite. }\end{array}$ & \\
\hline 7. & $\begin{array}{l}\text { Aspergillus } \\
\text { fumigatus }\end{array}$ & Fungal keratitis & Wnt5a & $\begin{array}{l}\text { Host PRR activates Wnt5A expression through ERK and JNK } \\
\text { pathway. Wnt5A attracts neutrophils for clearance of Aspergillus } \\
\text { fumigatus. }\end{array}$ & $(65)$ \\
\hline
\end{tabular}

with host immune programs against infections (78-81). In this context, the microbiota of the gut deserve special mention on account of their prominent prevalence in several niches of the gut especially the Peyer's patches and the lamina propria (82). These microbiota exist both in the gut lumen as well as in close proximity with different kinds of macrophages and contribute to immune regulation in the host. For instance, although not clearly understood how, gut microbiota are required for the maintenance of $\operatorname{sIgA}$ and a steady state cytokine milieu in the gut lumen, which can potentially serve to fight off pathogens (78, $83,84)$. Gut microbiota are also known to secrete antibacterial peptides, which are required for immune defense $(10,85)$.

Wnt signaling is important for gut organogenesis $(86,87)$ and sustains intestinal homeostasis through maintenance of specific microflora. Several lines of evidence suggest that colonization of microbiota in specific gut regions correlates with differential expression of Wnts such as Wnt5A and Wnt $3 \mathrm{~A}$, and Wnt signaling intermediates for example $\beta$-catenin (9). Wnt signaling components such as Axin and Disheveled on the other hand, have been shown to act synergistically with Synbindin, a syndecan-2 binding protein, to influence gut microbiota composition (88). How the apparent symbiosis between Wnt signaling and gut microbiota composition relates to immune defense, however remains undocumented. In view of the fact that Wnt signaling, in particular Wnt5 A signaling facilitates internalization and destruction of several pathogens through its influence on the cytoskeletal dynamics and autophagy machinery of the host macrophage $(3,4)$, but coordinates with the resident host microbiota (9), it is quite evident that Wnt signaling is able to differentiate pathogen from non-pathogen. But, how does this happen? Although there is evidence that some microbiota are present within the resident phagocytes $(89,90)$, it is unclear if the microbial niche is created or promoted by Wnt signaling and how it relates to the cytoskeletal actin network. It also remains to be seen if host resident microbiota influences the phagocytosis and clearance of pathogenic microbes and whether such interrelation involves Wnt signaling.

\section{CONCLUSION AND FUTURE DIRECTIONS}

Complex Wnt signaling schemes that are intrinsically associated with macrophage mediated immune functions (e.g., phagocytosis, autophagy/xenophagy) conform to the in-built maneuvering of macrophages as they confront with different kinds of pathogens $(1,91)$. Several lines of evidence substantiate that Wnt signaling, in particular Wnt5A signaling, 
is important for the cytoskeletal modulations and transcriptional programs inherent to macrophages during immune surveillance $(3,4,6)$. While many pathogens are disabled through activation of Wnt5A signaling, some pathogens utilize it for their own survival within the host macrophage $(3,4,7,8,65)$. Moreover, although not known exactly how, colonization of distinct microbiota within the lumen and macrophage associated niches within the gut and other anatomical locations correlate with differential expression of different Wnts and their signaling intermediates (9). The different nuances of Wnt signaling that annihilate some microbes, yet allow the growth and proliferation of others, at the same time sustaining the colonization of diverse microbiota, remain largely uncharacterized. In this regard one may come up with several explanations. In light of the fact that Wnt5A signaling alters actin assembly $(3,4,30)$, a vital component of host pathogen interaction, it is possible that Wnt5A induced alterations in actin assembly influence different pathogens differently, depending on the nature of virulence factors, thereby either inhibiting or facilitating their survival. The situation perhaps is guided by the extent of Wnt5A signaling in macrophages, as we observed inhibition of infection by pathogenic microbes through activation of Wnt5A signaling and increased infection through its blockade $(3,4)$. The decision for pathogen destruction vis. a vis. survival is possibly based on the nature of the tussle between host induced and pathogen induced modulations (conformations) of actin and actin binding proteins in the very early stages of infection wherein host Wnt5A signaling plays a fundamental role. In this connection, knowledge of the status of the macrophage associated resident microbiota, in relation to Wnt signaling and cytoskeletal dynamics is vital.

In future, the influence of Wnt signaling on actin modulations at the initial stages of infection needs to be deciphered at the molecular level in the context of different microbes, ranging from virulent pathogens to the resident microbiota, which may

\section{REFERENCES}

1. Gordon S. The macrophage: past, present and future. Eur J Immunol. (2007) 37:S9-17. doi: 10.1002/eji.200737638

2. Guha I, Naskar D, Sen M. Macrophage as a mediator of immune response: sustenance of immune homeostasis. Macrophage. (2015) 2:1-9. doi: 10.14800/macrophage.709

3. Jati S, Kundu S, Chakraborty A, Mahata SK, Nizet V, Sen M. Wnt5A signaling promotes defense against bacterial pathogens by activating a host autophagy circuit. Front Immunol. (2018) 9:679. doi: 10.3389/fimmu.2018. 00679

4. Chakraborty A, Kurati SP, Mahata SK, Sundar S, Roy S, Sen M. Wnt5a signaling promotes host defense against Leishmania donovani infection. J Immunol. (2017) 199:992-1002. doi: 10.4049/jimmunol.1601927

5. Maiti G, Naskar D, Sen M. The wingless homolog Wnt5a stimulates phagocytosis but not bacterial killing. Proc Natl Acad Sci USA. (2012) 109:16600-5. doi: 10.1073/pnas.1207789109

6. Naskar D, Maiti G, Chakraborty A, Roy A, Chattopadhyay D, Sen M. Wnt5a-Rac1-NF- B homeostatic circuitry sustains innate immune functions in macrophages. J Immunol. (2014) 192:4386-97. doi: $10.4049 /$ jimmunol.1302817

7. Volpini X, Ambrosio LF, Fozzatti L, Insfran C, Stempin CC, Cervi L, et al. Trypanosoma cruzi exploits Wnt signaling pathway to promote its be deemed as non-pathogens. Additionally, the potential links between the cytoskeletal actin dynamics and transcriptional programs need to be carefully assessed. In this connection, a good understanding of the cytokine milieu that correlates with the interaction of Wnt signaling with different microbial infections will be important, especially in view of its connection with the different stages of sepsis associated with pathogenic infections (92). A thorough evaluation of Wnt signaling in the context of microbial pathogenesis and colonization of resident microbiota may lead to the development of new modes of therapeutic interventions for the drug resistant refractory microbial infections.

\section{AUTHOR CONTRIBUTIONS}

MS organized the layout of the article and wrote the article. DN contributed to the layout organization and writing. SJ and TS worked on the table and references and assisted in writing.

\section{FUNDING}

This work was supported by funding from DBT, Govt. of India, Ministry of Science and Technology (BT/PR27125/BRB/10/1635/2017), and Institutional funding. SJ was supported by Research Scholar Fellowship from CSIR, Govt. of India, and by The Company of Biologists, Journal of Cell Biology. TRS was supported by Research Scholar Fellowship from CSIR, Govt. of India. DN was supported by DST-Inspire Faculty research scheme from DST, Govt. of India, Ministry of Science and Technology (DST/INSPIRE/04/2017/000675).

\section{ACKNOWLEDGMENTS}

We are thankful to G. Ghosh, UCSD for important suggestions and insightful comments during preparation of manuscript.

intracellular replication in macrophages. Front Immunol. (2018) 9:859. doi: 10.3389/fimmu.2018.00859

8. Luo T, Dunphy PS, Lina TT, McBride JW. Ehrlichia chaffeensis exploits canonical and noncanonical host Wnt signaling pathways to stimulate phagocytosis and promote intracellular survival. Infect Immun. (2016) 84:686-700. doi: 10.1128/IAI.01289-15

9. Neumann P-A, Koch S, Hilgarth RS, Perez-Chanona E, Denning P, Jobin $\mathrm{C}$, et al. Gut commensal bacteria and regional Wnt gene expression in the proximal versus distal colon. Am J Pathol. (2014) 184:592-9. doi: 10.1016/j.ajpath.2013.11.029

10. Ubeda C, Djukovic A, Isaac S. Roles of the intestinal microbiota in pathogen protection. Clin Transl Immunol. (2017) 6:e128. doi: 10.1038/cti.2017.2

11. Nusse R, van Ooyen A, Cox D, Fung YK, Varmus H. Mode of proviral activation of a putative mammary oncogene (int-1) on mouse chromosome 15. Nature. (1984) 307:131-6. doi: 10.1038/307131a0

12. The Wnt Homepage. Available online at: https://web.stanford.edu/group/ nusselab/cgi-bin/wnt/ (accessed January 31, 2019).

13. Nusse R, Varmus H. Three decades of Wnts: a personal perspective on how a scientific field developed. EMBO J. (2012) 31:2670-84. doi: 10.1038/emboj.2012.146

14. Sharma RP, Chopra VL. Effect of the wingless (wg1) mutation on wing and haltere development in Drosophila melanogaster. Dev Biol. (1976) 48:461-5. doi: 10.1016/0012-1606(76)90108-1 
15. Babu P. Early developmental subdivisions of the wing disk in Drosophila. Molec Gen Genet. (1977) 151:289-94. doi: 10.1007/BF00268792

16. Cadigan KM, Nusse R. Wnt signaling: a common theme in animal development. Genes Dev. (1997) 11:3286-305. doi: 10.1101/gad.11.24.3286

17. Janda CY, Waghray D, Levin AM, Thomas C, Garcia KC. Structural basis of Wnt recognition by Frizzled. Science. (2012) 337:59-64. doi: $10.1126 /$ science. 1222879

18. Sato A, Yamamoto H, Sakane H, Koyama H, Kikuchi A. Wnt5a regulates distinct signalling pathways by binding to Frizzled2. EMBO J. (2010) 29:41-54. doi: $10.1038 /$ emboj.2009.322

19. He X, Saint-Jeannet J-P, Wang Y, Nathans J, Dawid I, Varmus H. A member of the frizzled protein family mediating axis induction by Wnt-5A. Science. (1997) 275:1652-4. doi: 10.1126/science.275.5306.1652

20. Schulte G, Bryja V. The Frizzled family of unconventional Gprotein-coupled receptors. Trends Pharmacol Sci. (2007) 28:518-25. doi: 10.1016/j.tips.2007.09.001

21. Green J, Nusse R, van Amerongen R. The role of Ryk and Ror receptor tyrosine kinases in Wnt signal transduction. Cold Spring Harb Perspect Biol. (2014) 6:a009175. doi: 10.1101/cshperspect.a009175

22. Green JL, Kuntz SG, Sternberg PW. Ror receptor tyrosine kinases: orphans no more. Trends Cell Biol. (2008) 18:536-44. doi: 10.1016/j.tcb.2008.08.006

23. Dijksterhuis JP, Petersen J, Schulte G. International union of basic and clinical pharmacology review: WNT/Frizzled signalling: receptor-ligand selectivity with focus on FZD-G protein signalling and its physiological relevance: IUPHAR review 3. Br J Pharmacol. (2014) 171:1195-209. doi: 10.1111/bph.12364

24. Mikels AJ, Nusse R. Purified Wnt5a protein activates or inhibits $\beta$-cateninTCF signaling depending on receptor context. PLoS Biol. (2006) 4:e115. doi: 10.1371/journal.pbio.0040115

25. Sen M, Ghosh G. Transcriptional outcome of Wnt-Frizzled signal transduction in inflammation: evolving concepts. J Immunol. (2008) 181:4441-5. doi: 10.4049/jimmunol.181.7.4441

26. Gordon MD, Nusse R. Wnt signaling: multiple pathways, multiple receptors, and multiple transcription factors. J Biol Chem. (2006) 281:22429-33. doi: $10.1074 /$ jbc.R600015200

27. Clevers H. Wnt/ $\beta$-catenin signaling in development and disease. Cell. (2006) 127:469-80. doi: 10.1016/j.cell.2006.10.018

28. Kühl M, Sheldahl LC, Park M, Miller JR, Moon RT. The Wnt/Ca2+ pathway: a new vertebrate Wnt signaling pathway takes shape. Trends Genet. (2000) 16:279-83. doi: 10.1016/S0168-9525(00)02028-X

29. Gregory MA, Phang TL, Neviani P, Alvarez-Calderon F, Eide CA, O'Hare $\mathrm{T}$, et al. Wnt/Ca2+/NFAT signaling maintains survival of $\mathrm{Ph}+$ leukemia cells upon inhibition of Bcr-Abl. Cancer Cell. (2010) 18:74-87. doi: $10.1016 /$ j.ccr.2010.04.025

30. Witze ES, Litman ES, Argast GM, Moon RT, Ahn NG. Wnt5a control of cell polarity and directional movement by polarized redistribution of adhesion receptors. Science. (2008) 320:365-9. doi: 10.1126/science.1151250

31. Witze ES, Connacher MK, Houel S, Schwartz MP, Morphew MK, Reid $\mathrm{L}$, et al. Wnt5a directs polarized calcium gradients by recruiting cortical endoplasmic reticulum to the cell trailing edge. Dev Cell. (2013) 26:645-57. doi: 10.1016/j.devcel.2013.08.019

32. Mostowy S, Shenoy AR. The cytoskeleton in cell-autonomous immunity: structural determinants of host defence. Nat Rev Immunol. (2015) 15:559-73. doi: $10.1038 /$ nri3877

33. Grumolato L, Liu G, Mong P, Mudbhary R, Biswas R, Arroyave R, et al. Canonical and noncanonical Wnts use a common mechanism to activate completely unrelated coreceptors. Genes Dev. (2010) 24:2517-30. doi: 10.1101/gad.1957710

34. Qi J, Lee H-J, Saquet A, Cheng X-N, Shao M, Zheng JJ, et al. Autoinhibition of Dishevelled protein regulated by its extreme $\mathrm{C}$ terminus plays a distinct role in Wnt/ $\beta$-catenin and Wnt/planar cell polarity (PCP) signaling pathways. J Biol Chem. (2017) 292:5898-908. doi: 10.1074/jbc.M116.772509

35. Lee H-J, Shi D-L, Zheng JJ. Conformational change of Dishevelled plays a key regulatory role in the Wnt signaling pathways. Elife. (2015) 4:e08142. doi: 10.7554/eLife.08142

36. Aznar N, Midde KK, Dunkel Y, Lopez-Sanchez I, Pavlova Y, Marivin A, et al. Daple is a novel non-receptor GEF required for trimeric $G$ protein activation in Wnt signaling. Elife. (2015) 4:e07091. doi: 10.7554/eLife.07091
37. Sheng R, Kim H, Lee H, Xin Y, Chen Y, Tian W, et al. Cholesterol selectively activates canonical Wnt signalling over non-canonical Wnt signalling. Nat Commun. (2014) 5:4393. doi: 10.1038/ncomms5393

38. Aznar N, Ear J, Dunkel Y, Sun N, Satterfield K, He F, et al. Convergence of Wnt, growth factor, and heterotrimeric G protein signals on the guanine nucleotide exchange factor Daple. Sci Signal. (2018) 11:eaa04220. doi: 10.1126/scisignal.aao4220

39. Hara K, Kageji T, Mizobuchi Y, Kitazato KT, Okazaki T, Fujihara T, et al. Blocking of the interaction between Wnt proteins and their co-receptors contributes to the anti-tumor effects of adenovirusmediated DKK3 in glioblastoma. Cancer Lett. (2015) 356:496-505. doi: $10.1016 /$ j.canlet.2014.09.045

40. Mehmeti M, Bergenfelz C, Källberg E, Millrud CR, Björk P, Ivars F, et al. Wnt5a is a TLR2/4-ligand that induces tolerance in human myeloid cells. Commun Biol. (2019) 2:176. doi: 10.1038/s42003-019-0432-4

41. Chae W-J, Bothwell ALM. Canonical and non-canonical Wnt signaling in immune cells. Trends Immunol. (2018) 39:830-47. doi: 10.1016/j.it.2018.08.006

42. Zhang Y, Wu S, Xia Y, Chen D, Petrof EO, Claud EC, et al. Axin1 prevents salmonella invasiveness and inflammatory response in intestinal epithelial cells. PLoS ONE. (2012) 7:e34942. doi: 10.1371/journal.pone.0034942

43. Liu X, Wu S, Xia Y, Li XE, Xia Y, Zhou ZD, et al. Wingless homolog Wnt11 suppresses bacterial invasion and inflammation in intestinal epithelial cells. Am J Physiol Gastrointest Liver Physiol. (2011) 301:G992-1003. doi: 10.1152/ajpgi.00080.2011

44. Acting on Actin During Bacterial Infection. IntechOpen. Available online at: https://www.intechopen.com/books/cytoskeleton-structure-dynamicsfunction-and-disease/acting-on-actin-during-bacterial-infection (accessed September 2, 2019).

45. The Actin Cytoskeleton and Bacterial Infection. SpringerLink. Available online at: https://link.springer.com/book/10.1007/978-3-319-50047-8 (accessed September 2, 2019).

46. Chen K, Fu Q, Li D, Wu Y, Sun S, Zhang X. Wnt3a suppresses Pseudomonas aeruginosa-induced inflammation and promotes bacterial killing in macrophages. Mol Med Rep. (2016) 13:2439-46. doi: 10.3892/mmr.2016.4869

47. Schaale K, Brandenburg J, Kispert A, Leitges M, Ehlers S, Reiling N. Wnt6 is expressed in granulomatous lesions of Mycobacterium tuberculosis-infected mice and is involved in macrophage differentiation and proliferation. $J$ Immunol. (2013) 191:5182-95. doi: 10.4049/jimmunol.1201819

48. Schaale K, Neumann J, Schneider D, Ehlers S, Reiling N. Wnt signaling in macrophages: augmenting and inhibiting mycobacteriainduced inflammatory responses. Eur J Cell Biol. (2011) 90:553-9. doi: 10.1016/j.ejcb.2010.11.004

49. Villaseñor T, Madrid-Paulino E, Maldonado-Bravo R, Urbán-Aragón A, Pérez-Martínez L, Pedraza-Alva G. Activation of the Wnt pathway by Mycobacterium tuberculosis: a Wnt-Wnt situation. Front Immunol. (2017) 8:50. doi: $10.3389 /$ fimmu.2017.00050

50. Blumenthal A, Ehlers S, Lauber J, Buer J, Lange C, Goldmann T, et al. The Wingless homolog WNT5A and its receptor Frizzled-5 regulate inflammatory responses of human mononuclear cells induced by microbial stimulation. Blood. (2006) 108:965-73. doi: 10.1182/blood-2005-12-5046

51. Chen D, Li G, Fu X, Li P, Zhang J, Luo L. Wnt5a deficiency regulates inflammatory cytokine secretion, polarization, and apoptosis in Mycobacterium tuberculosis-infected macrophages. DNA Cell Biol. (2017) 36:58-66. doi: 10.1089/dna.2016.3418

52. Brandenburg J, Reiling N. The Wnt blows: on the functional role of Wnt signaling in Mycobacterium tuberculosis infection and beyond. Front Immunol. (2016) 7:635. doi: 10.3389/fimmu.2016.00635

53. Neumann J, Schaale K, Farhat K, Endermann T, Ulmer AJ, Ehlers S, et al. Frizzled 1 is a marker of inflammatory macrophages, and its ligand Wnt3a is involved in reprogramming Mycobacterium tuberculosis-infected macrophages. FASEB J. (2010) 24:4599-612. doi: 10.1096/fj.10-160994

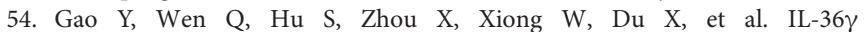
promotes killing of Mycobacterium tuberculosis by macrophages via WNT5Ainduced noncanonical WNT signaling. J Immunol. (2019) 203:922-35. doi: 10.4049/jimmunol.1900169

55. Seto S, Tsujimura K, Koide Y. Coronin-1a inhibits autophagosome formation around Mycobacterium tuberculosis-containing phagosomes and assists 
mycobacterial survival in macrophages. Cell Microbiol. (2012) 14:710-27. doi: $10.1111 / j .1462-5822.2012 .01754 . x$

56. Guérin I, de Chastellier C. Pathogenic mycobacteria disrupt the macrophage actin filament network. Infect Immun. (2000) 68:2655-62. doi: 10.1128/IAI.68.5.2655-2662.2000

57. Song O-R, Queval CJ, Iantomasi R, Delorme V, Marion S, VeyronChurlet R, et al. ArfGAP1 restricts Mycobacterium tuberculosis entry by controlling the actin cytoskeleton. EMBO Rep. (2018) 19:29-42. doi: $10.15252 / \mathrm{embr} .201744371$

58. Abidin BM, Hammami A, Stäger S, Heinonen KM. Infection-adapted emergency hematopoiesis promotes visceral leishmaniasis. PLOS Pathog. (2017) 13:e1006422. doi: 10.1371/journal.ppat.1006422

59. Cotterell SEJ, Engwerda CR, Kaye PM. Leishmania donovani infection of bone marrow stromal macrophages selectively enhances myelopoiesis, by a mechanism involving GM-CSF and TNF- $\alpha$. Blood. (2000) 95:1642-51. doi: 10.1182/blood.V95.5.1642.005k10_1642_1651

60. Ali N, Hussain S. Leishmania donovani bodies in bone marrow. Clin Case Rep. (2014) 2:238-9. doi: 10.1002/ccr3.97

61. Staal FJT, Clevers HC. WNT signalling and haematopoiesis: a WNT-WNT situation. Nat Rev Immunol. (2005) 5:21. doi: 10.1038/nri1529

62. Famili F, Naber BAE, Vloemans S, Haas EFE de, Tiemessen MM, Staal FJT. Discrete roles of canonical and non-canonical Wnt signaling in hematopoiesis and lymphopoiesis. Cell Death Dis. (2015) 6:e1981. doi: $10.1038 /$ cddis.2015.326

63. Nemeth MJ, Topol L, Anderson SM, Yang Y, Bodine DM. Wnt5a inhibits canonical Wnt signaling in hematopoietic stem cells and enhances repopulation. Proc Natl Acad Sci USA. (2007) 104:15436-41. doi: 10.1073/pnas.0704747104

64. Corrigan PM, Dobbin E, Freeburn RW, Wheadon H. Patterns of Wnt/Fzd/LRP gene expression during embryonic hematopoiesis. Stem Cell Dev. (2009) 18:759-72. doi: 10.1089/scd.2008.0270

65. Che C, Li C, Lin J, Zhang J, Jiang N, Yuan K, et al. Wnt5a contributes to dectin-1 and LOX-1 induced host inflammatory response signature in Aspergillus fumigatus keratitis. Cell Signal. (2018) 52:103-11. doi: 10.1016/j.cellsig.2018.08.020

66. Kaye P, Scott P. Leishmaniasis: complexity at the host-pathogen interface. Nat Rev Microbiol. (2011) 9:604-15. doi: 10.1038/nrmicro2608

67. Classen A. Pseudomonas aeruginosa. Mechanisms of Pathogenicity. (2017) Available online at: https://mechpath.com/2017/12/08/pseudomonasaeruginosa/ (accessed May 30, 2019).

68. Kobayashi GS. Disease mechanisms of fungi. In: Baron S, editor. Medical Microbiology. Galveston, TX: University of Texas Medical Branch at Galveston. Available online at: http://www.ncbi.nlm.nih.gov/books/ NBK8103/ (accessed June 1, 2019).

69. Olson EN, Nordheim A. Linking actin dynamics and gene transcription to drive cellular motile functions. Nat Rev Mol Cell Biol. (2010) 11:353-65. doi: $10.1038 / \mathrm{nrm} 2890$

70. Huang Y, Haas C, Ghadiali SN. Influence of transmural pressure and cytoskeletal structure on NF- $\mathrm{kB}$ activation in respiratory epithelial cells. Cell Mol Bioeng. (2010) 3:415-27. doi: 10.1007/s12195-010-0138-7

71. Sha WC, Liou HC, Tuomanen EI, Baltimore D. Targeted disruption of the p50 subunit of NF-kappa B leads to multifocal defects in immune responses. Cell. (1995) 80:321-30. doi: 10.1016/0092-8674(95)90415-8

72. Dev A, Iyer S, Razani B, Cheng G. NF-кB and innate immunity. In: Karin M. NF-kB in Health and Disease Current Topics in Microbiology and Immunology. Berlin; Heidelberg: Springer Berlin Heidelberg (2011). p. 11543. doi: 10.1007/82_2010_102

73. Li Q, Verma IM. NF-KB regulation in the immune system. Nat Rev Immunol. (2002) 2:725. doi: $10.1038 /$ nri910

74. Sen M, Chamorro M, Reifert J, Corr M, Carson DA. Blockade of Wnt5A/Frizzled 5 signaling inhibits rheumatoid synoviocyte activation. Arthritis Rheum. (2001) 44:772-81. doi: 10.1002/1529-0131(200104)44:4\&lt;772::AIDANR133\&gt;3.0.CO;2-L

75. Campos SB, Ashworth SL, Wean S, Hosford M, Sandoval RM, Hallett $\mathrm{MA}$, et al. Cytokine-induced F-actin reorganization in endothelial cells involves RhoA activation. Am J Physiol. (2009) 296:F487. doi: 10.1152/ajprenal.00112.2008

76. Ostler N, Britzen-Laurent N, Liebl A, Naschberger E, Lochnit G, Ostler M, et al. Gamma interferon-induced guanylate binding protein 1 is a novel actin cytoskeleton remodeling factor. Mol Cell Biol. (2014) 34:196-209. doi: 10.1128/MCB.00664-13

77. Wojciak-Stothard B, Entwistle A, Garg R, Ridley AJ. Regulation of TNFalpha-induced reorganization of the actin cytoskeleton and cell-cell junctions by Rho, Rac, and Cdc42 in human endothelial cells. J Cell Physiol. (1998) 176:150-65. doi: 10.1002/(SICI) 1097-4652(199807)176:1<150::AID-JCP17>3. 0.CO;2-B

78. Lycke NY, Bemark M. The role of Peyer's patches in synchronizing gut IgA responses. Front Immunol. (2012) 3:329. doi: 10.3389/fimmu.2012.00329

79. Belkaid Y, Hand T. Role of the microbiota in immunity and inflammation. Cell. (2014) 157:121-41. doi: 10.1016/j.cell.2014.03.011

80. Chu H, Mazmanian SK. Innate immune recognition of the microbiota promotes host-microbial symbiosis. Nat Immunol. (2013) 14:668-75. doi: $10.1038 /$ ni.2635

81. Levy M, Thaiss CA, Elinav E. Metabolites: messengers between the microbiota and the immune system. Genes Dev. (2016) 30:1589-97. doi: 10.1101/gad.284091.116

82. Jung C, Hugot J-P, Barreau F. Peyer's patches: the immune sensors of the intestine. Int J Inflam. (2010) 2010:823710. doi: 10.4061/2010/ 823710

83. Rey J, Garin N, Spertini F, Corthésy B. Targeting of secretory IgA to Peyer's patch dendritic and $\mathrm{T}$ cells after transport by intestinal $\mathrm{M}$ cells. J Immunol. (2004) 172:3026-33. doi: 10.4049/jimmunol.172.5.3026

84. Breedveld A, van Egmond M. IgA and FcaRI: pathological roles and therapeutic opportunities. Front Immunol. (2019) 10:553. doi: 10.3389/fimmu.2019.00553

85. Zipperer A, Konnerth MC, Laux C, Berscheid A, Janek D, Weidenmaier C, et al. Human commensals producing a novel antibiotic impair pathogen colonization. Nature. (2016) 535:511-6. doi: 10.1038/nature18634

86. Verzi MP, Shivdasani RA. Wnt signaling in gut organogenesis. Organogenesis. (2008) 4:87-91. doi: 10.4161/org.4.2.5854

87. Swafford D, Shanmugam A, Ranganathan P, Hussein MS, Koni PA, Prasad $\mathrm{PD}$, et al. Canonical Wnt signaling in CD11c+ APCs regulates microbiotainduced inflammation and immune cell homeostasis in the colon. J Immunol. (2018) 200:3259-68. doi: 10.4049/jimmunol.1701086

88. Ai L, Ren Y, Li Y, Chen H, Qian Y, Lu S, et al. Synbindin deficiency inhibits colon carcinogenesis by attenuating Wnt cascade and balancing gut microbiome. Int $J$ Cancer. (2019) 145:206-20. doi: 10.1002/ijc. 32074

89. Morikawa M, Tsujibe S, Kiyoshima-Shibata J, Watanabe Y, Kato-Nagaoka $\mathrm{N}$, Shida $\mathrm{K}$, et al. Microbiota of the small intestine is selectively engulfed by phagocytes of the lamina propria and Peyer's patches. PLoS ONE. (2016) 11:e0163607. doi: 10.1371/journal.pone.0163607

90. Rios D, Wood MB, Li J, Chassaing B, Gewirtz AT, Williams IR. Antigen sampling by intestinal $\mathrm{M}$ cells is the principal pathway initiating mucosal IgA production to commensal enteric bacteria. Mucosal Immunol. (2016) 9:907-16. doi: 10.1038/mi.2015.121

91. Gordon S. Phagocytosis: an immunobiologic process. Immunity. (2016) 44:463-75. doi: 10.1016/j.immuni.2016.02.026

92. Gatica-Andrades M, Vagenas D, Kling J, Nguyen TTK, Benham H, Thomas R, et al. WNT ligands contribute to the immune response during septic shock and amplify endotoxemia-driven inflammation in mice. Blood Adv. (2017) 1:1274-86. doi: 10.1182/bloodadvances.2017006163

Conflict of Interest: The authors declare that the research was conducted in the absence of any commercial or financial relationships that could be construed as a potential conflict of interest.

The reviewer JM declared their collaboration with one of the authors MS as co-editors in the Research Topic and confirmed the absence of any other collaboration to the handling editor.

Copyright (c) 2019 Jati, Sarraf, Naskar and Sen. This is an open-access article distributed under the terms of the Creative Commons Attribution License (CC BY). The use, distribution or reproduction in other forums is permitted, provided the original author(s) and the copyright owner(s) are credited and that the original publication in this journal is cited, in accordance with accepted academic practice. No use, distribution or reproduction is permitted which does not comply with these terms. 